\title{
Torsional Strengthening of RC Beams with Near-Surface Mounted Steel Bars
}

\author{
Nasih Habeeb Askandar $\mathbb{D}^{1,2}$ and Abdulkareem Darweesh Mahmood $\mathbb{D i D}^{2}$ \\ ${ }^{1}$ Halabja Technical College of Applied Sciences, Sulaimani Polytechnic University, Sulaymaniyah, Iraq \\ ${ }^{2}$ Department of Civil Engineering, Salahaddin University, Erbil, Iraq \\ Correspondence should be addressed to Nasih Habeeb Askandar; nasih.askandar@spu.edu.iq
}

Received 26 July 2019; Revised 3 February 2020; Accepted 6 February 2020; Published 18 March 2020

Academic Editor: Paulo Reis

Copyright (c) 2020 Nasih Habeeb Askandar and Abdulkareem Darweesh Mahmood. This is an open access article distributed under the Creative Commons Attribution License, which permits unrestricted use, distribution, and reproduction in any medium, provided the original work is properly cited.

\begin{abstract}
The strength of reinforced concrete members can be enhanced by using the externally bonded reinforcement (EBR) and nearsurface mounted (NSM) methods. However, very few studies have adopted the NSM method for torsional strengthening. Although previous studies have reported the efficacy of using epoxy-resin-bonded NSM steel bars in increasing the flexural and shear strength of RC beams, no study has examined the use of steel bars and epoxy adhesives for torsional strengthening. Therefore, this study investigates the behaviour of RC beams subjected to the combined actions of torsion and bending moment when they are strengthened with NSM steel bars $(\varnothing 10 \mathrm{~mm})$ in different configurations. The practical part of this investigation consisted of seven cast and tested beams of $150 \times 250 \times 2000 \mathrm{~mm}$ dimensions. One beam was reference, which is not strengthened; meanwhile, all the other beams were strengthened with two U-shape-welded NSM steel bars. During the testing process, the twist angle at the torque intervals, first cracking torque, ultimate torque, and ultimate twist angle of the conventional beam were compared with those of the strengthened beams. The torsional performance of the RC beams was significantly improved by using NSM steel bars, whereas in various NSM configurations, the $90^{\circ}$ NSM beams outperformed the $45^{\circ}$ NSM beams.
\end{abstract}

\section{Introduction}

A considerable amount of torque can accumulate in many concrete members, including curved bridge elements, spandrel beams, horizontally curved members, and eccentrically loaded beams. The torsional capacity of these members needs to be maximised due to several factors, including structural damage, deterioration, eccentricity in loading, skewness, curved box girders, and increased loading.

Strengthening materials can be applied to RC elements in two techniques, namely, (1) the externally bonded reinforcement (EBR) method, where the strengthening materials are externally applied to the concrete surface, and (2) the near-surface mounted (NSM) method, where the strengthening materials are inserted within grooves that are precut into the concrete cover [1].
Considered as a proper alternative to the EBR method, the NSM strengthening technique comprises cutting grooves in the concrete cover of a specimen and then inserting rods into the grooves by using an adhesive. The NSM method presents numerous advantages over the EBR method, including its higher bonding productivity and better protection. The NSM method can also address the limitation of the EBR method in its maximum strain, which is lower than the ultimate strain due to premature debonding. The greater confinement granted by the adhesive and the surrounding concrete is considered the best advantage provided by the NSM method [2]. This strengthening technique has already been proven to be effective for the shear strengthening [3-6] and flexural strengthening of RC beams [7-22]. Many studies have used conventional steel bars instead of FRP materials for beam strengthening by employing the NSM method [21, 23-29]. 
However, only few studies [30, 31] have investigated the application of the NSM method in torsion strengthening. For example, Al-Bayati et al. [30] tested 10 beam specimens, with two beams serving as controls and the other eight beams strengthened by applying CFRP laminates to their four sides. These beams were inserted into grooves by using the NSM method. An epoxy adhesive was used in four strengthened beams and a modified cement-based adhesive was adapted as a replacement for epoxy in the other four beams. In [31], Al-Bayati et al. applied the same torsion strengthening technique, but instead of applying CFRP laminates to the four sides of the beam, they tied a CFRP rope around the cross section of beams with an equivalent carbon fibre percentage. In their experiment, they used a cement-based adhesive and tested four beams: two matching control beams and two supplemental beams, where torsion has been strengthened by using a CFRP rope and epoxy. They applied the same strengthening method for the two strengthened beams to test the consistency of their findings.

Many studies have applied the NSM FRP strengthening method to improve the flexural and shear strength of RC beams [3-22], whilst others have used conventional steel bars instead of FRP materials for flexural and shear strengthening [21-28]. However, only few of these studies have focused on torsion strengthening [29-31, 32] and no previous work has investigated the application of conventional steel bars for the torsion strengthening of RC beams. To fill this research gap, this study examines the characteristics of RC beams subjected to the combined actions of torsion and bending moment when they are strengthened by NSM steel bars in different configurations.

\section{Experimental Study}

2.1. Torsion Strengthening Configurations. Seven rectangular RC beams with $250 \mathrm{~mm}$ depth, $150 \mathrm{~mm}$ width, and $2000 \mathrm{~mm}$ length were cast by using ready-mixed concrete. The central part of these beams was specifically designed to display torsion failure. The length of the central part was set to $1.0 \mathrm{~m}$ to allow the formation of at least one spiral crack at the $45^{\circ}$ angle in the longitudinal axis of these beams. The steel reinforcement details and cross-section dimensions of each beam are presented in Figure 1. All beams were underreinforced, with respect to resisting torsional moment, according to the American Concrete Institute code ACI 31814 [33] to simulate torsion-deficient beams under some future loading conditions. The minimum spacing of the transverse reinforcement was also purposefully exceeded to facilitate the observation of torsional failure and to hinder the stirrup from restricting the torsional cracks. Figure 2 presents the groove details for all six strengthened beams. Grooves $20 \mathrm{~mm}$ wide and $20 \mathrm{~mm}$ deep were cut in the $25 \mathrm{~mm}$ cover zone of the concrete beams and two U-shaped conventional steel bars $(\varnothing 10 \mathrm{~mm})$, as shown in Figure 3, were embedded in these grooves. One of these steel bars had a U-shaped stirrup at the top, whilst the other bar had a U-shaped stirrup at its bottom. To create an enclosed circuit stirrup, these U-shaped steel bars were welded together with at least a $100 \mathrm{~mm}$ overlap between their legs. The strengthened beams were then divided into two groups. The beams in the first group have grooves with a $90^{\circ}$ angle of inclination with respect to the longitudinal axis, whilst those in the second group have grooves with a $45^{\circ}$ angle of inclination with respect to the longitudinal axis. The groove spacings for these beams were set to 100,150 , and $200 \mathrm{~mm}$.

2.2. Material Properties. Ready-mixed concrete was used for all seven beams. The compressive strength $\left(f^{\prime} c\right)$ of the supplied concrete was evaluated after 28 days. The average results of three concrete cylinders $(100 \mathrm{~mm}$ in diameter and $200 \mathrm{~mm}$ in height) on the day of the testing were considered for computing the compressive strength. Sikadur-30LP epoxy, a two-part epoxy that produces a clear liquid when mixed, was used as an adhesive to fill the grooves of the strengthened beams.

Three bars with similar diameters and three welded bars $(\varnothing 10 \mathrm{~mm})$ were subjected to uniaxial tensile tests to determine their yield and ultimate strength $\left(f_{y}, f_{u}\right)$ following the recommendations of ASTM A370-10 2010 [34]; stress-strain relationship of NSM steel bar is shown in Figure 4.

Table 1 summarises the mechanical properties of the concrete and NSM steel bars, the average compressive strength of the concrete $\left(f^{\prime} c\right)$, and the average test results for the steel bars, whilst Table 2 presents the properties of the epoxy based on the specifications supplied by the manufacturer.

2.3. Specimen Preparation. The installation of the strengthening steel bars began by cutting grooves into the concrete cover of the specimens after 28 days of curing. These grooves were cut in the transversal direction around the beam's cross section whilst maintaining dimensions greater than $1.5 \mathrm{db} \times 1.5 \mathrm{db}$ (where $\mathrm{db}$ denotes the diameter of the NSM steel reinforcement). A special concrete saw (Handle Grinder) with a diamond cutting saw blade was used for the cutting. A hammer drill and chisel were used to remove any remaining concrete lugs and to roughen the lower surface of the grooves. These grooves were then smoothened and cleaned with a wire brush and a highpressure air jet. The strengthening steel bars were bent into a U shape and two U-shaped steel bars were used for each closed groove (one at the top and the other at the bottom). In this way, these steel bars were overlapping for approximately $100 \mathrm{~mm}$ and welded together to form a closed stirrup at each round groove. These grooves were then filled with an epoxy adhesive groove filler (Sikadur-30LP) around the steel bar and the surface was levelled as shown in Figure 5. To ensure that the epoxy reached its full strength, the beams were stored for at least two weeks.

2.4. Test Setup and Instrumentation. The test set-up is presented in Figure 6. A 200-tonne hydraulic Jack was used to apply the load at the active support. The load had a $500 \mathrm{~mm}$ lever arm from the centroidal beam axis. A compression load cell with a capacity of 100 tonnes was used to measure the 


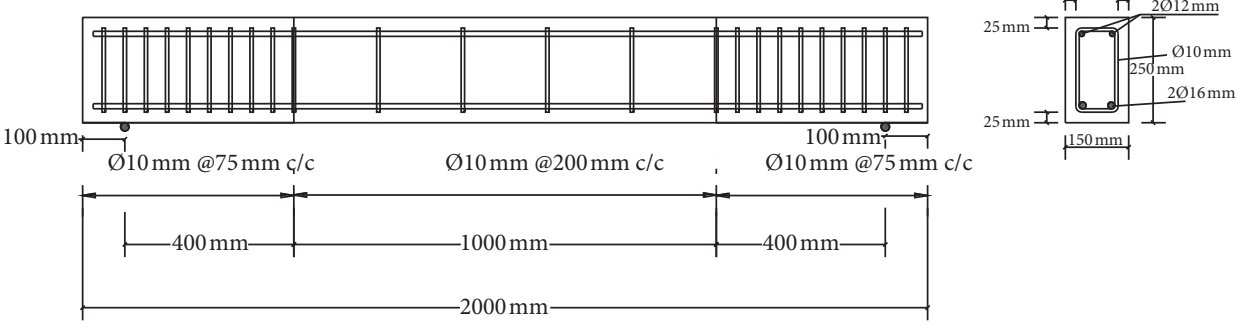

FIGURE 1: Dimensions and reinforcement details of the test beams.
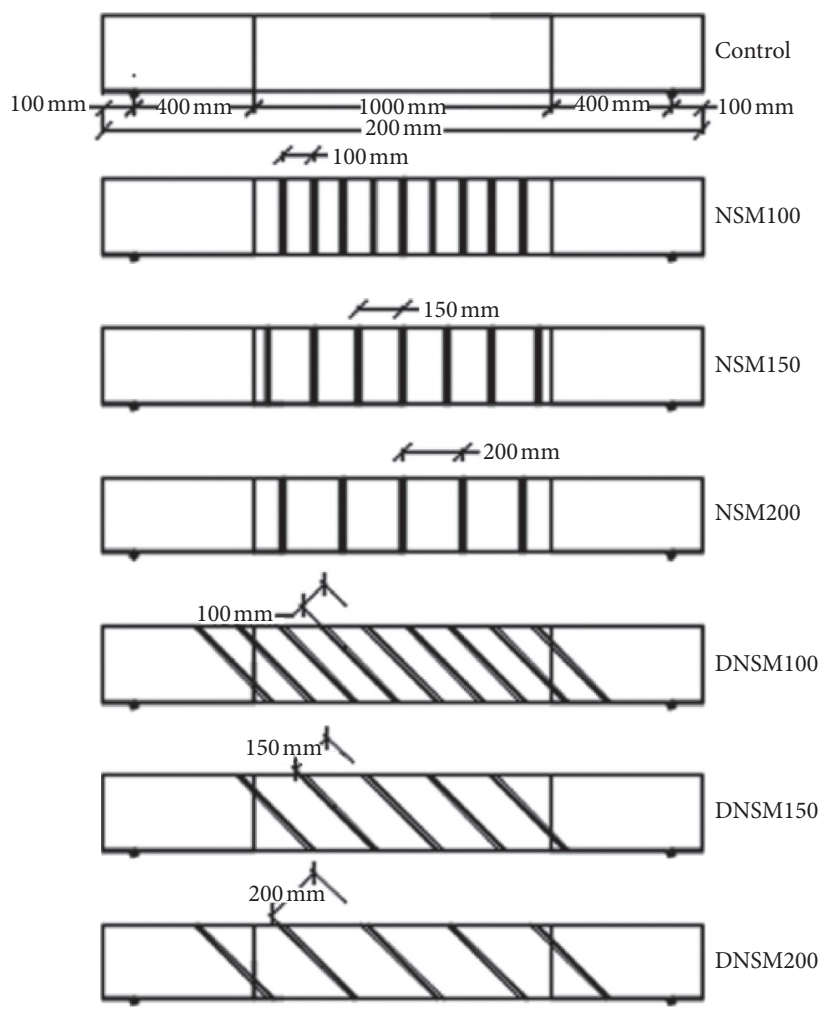

Figure 2: Strengthening of the test beams.

periodically applied load. The hydraulic Jack had a movable length of $250 \mathrm{~mm}$ and provided a $57.3^{\circ}$ twist capacity for the beam, the reaction arm had a $500 \mathrm{~mm}$ eccentricity from the centroidal axis of the beam, and the beam was longitudinally elongated after cracking. To avoid any longitudinal restriction and prevent any subsequent compression, the beam was permitted to slide and elongate freely by supporting the beam ends on rollers at the unresisting support. The twist angle of the free end (the point of applying the torque) was measured with the aid of the downward distance of the lever arm at that point by using a dial gauge.

The loading frame in the civil engineering laboratory was used to apply the load on the beam specimens. A special support condition that grants rotation about the longitudinal beam axis was arranged and the lever arms were attached to the specimen to provide torsional moment as shown in Figure 6. When the location of the lever arm coincides with the support, the specimen was subjected to pure torsion. To apply combined bending and torsion, the lever arm was kept beyond the two supports.

(i) Three dial gauges were used, of which two were used to measure the displacements under the lever arm and one was placed at the centre to measure central displacement.

(ii) A $400 \mathrm{~mm}$ distance was maintained between the centre of support and the lever arm to achieve bending along with torsion.

(iii) A load of the hydraulic Jack was transferred to the specimen by using the spreader beam that rests on the end of the lever arm attached to the specimen. In this case, half of the applied load was applied at the end of each lever arm.

(iv) The specimen that was placed between the supports had a $1.8 \mathrm{~m}$ length and $0.1 \mathrm{~m}$ projection outside the support. The central length of the specimen $(1.0 \mathrm{~m})$ was subjected to combined bending and torsion, whilst the $0.4 \mathrm{~m}$ length of the beam near each support was subjected to bending moment and shear force. The torque in the middle part of the specimen was computed by multiplying the load at the end of each lever arm (half of the total applied load) by the length of the lever arm from the centre of the specimen. The twist angle at each lever arm was calculated based on the vertical displacement of the lever arm end point and the length of the lever arm. The overall twist angle in the middle part of the specimen was calculated as the sum of twist angles at the couple of the lever arm.

2.5. Test Procedure. The hydraulic testing machine in the civil engineering laboratory as shown in Figure 7 was used to test the beam specimens.

The supports should be rotated and the applied load should be transferred from the centre of the machine to the two points that express the moment arm. The clamping loading frame used in this study is shown in Figures 5 and 6. This frame comprises an I-section $(200 \mathrm{~mm} \times 80 \mathrm{~mm} \times$ $8 \mathrm{~mm}$ ) that was welded to two steel channels $(100 \mathrm{~mm} \times$ $50 \mathrm{~mm} \times 8 \mathrm{~mm}$ ). These steel channels were connected from the bottom after being inserted around the beam's cross section by large bolts (with two bolts being used for each arm). The final test set-up was shaped like a bracket. The 


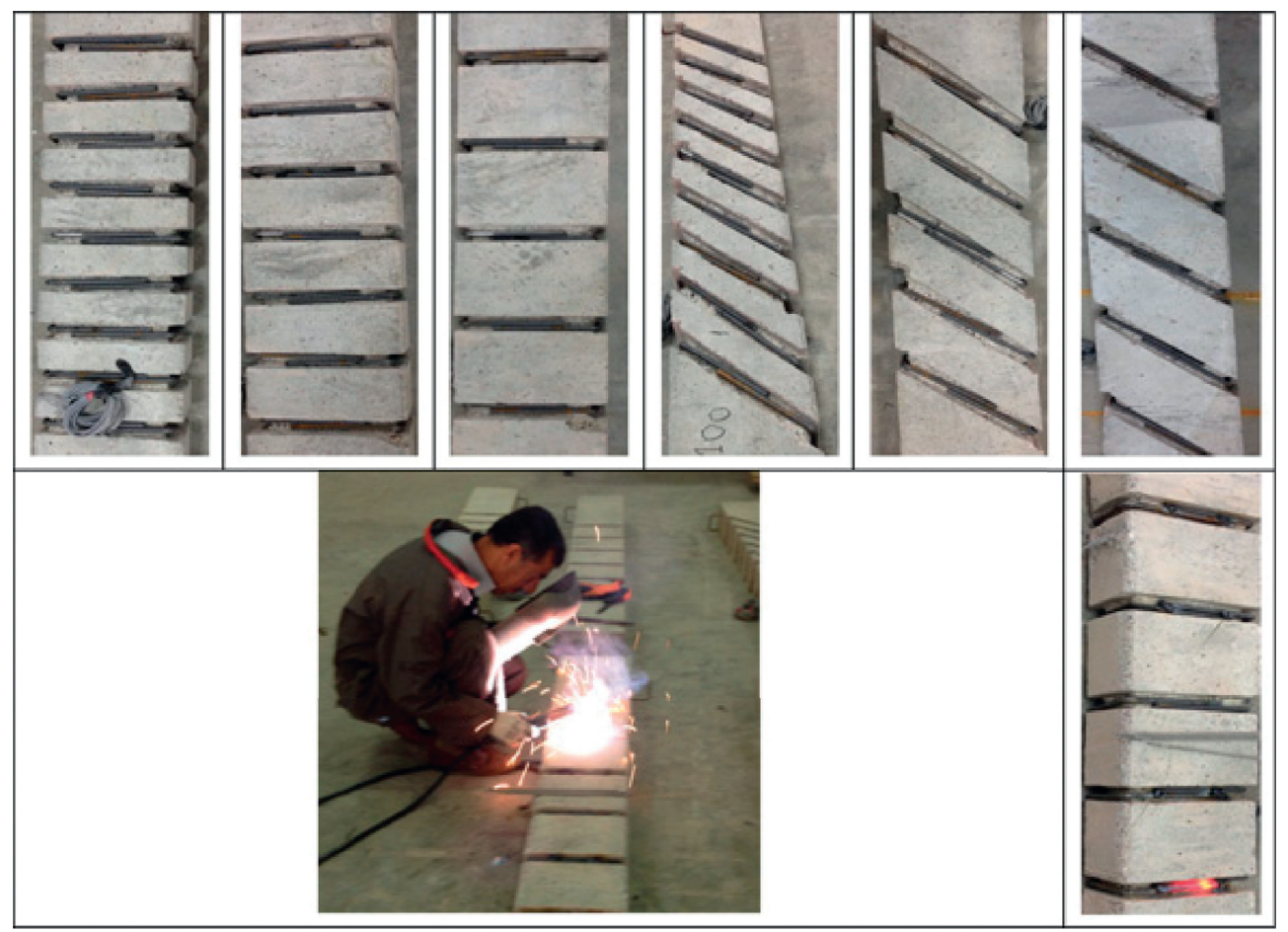

Figure 3: Two U-shaped welded conventional steel bars $(\varnothing 10 \mathrm{~mm})$ for each groove.

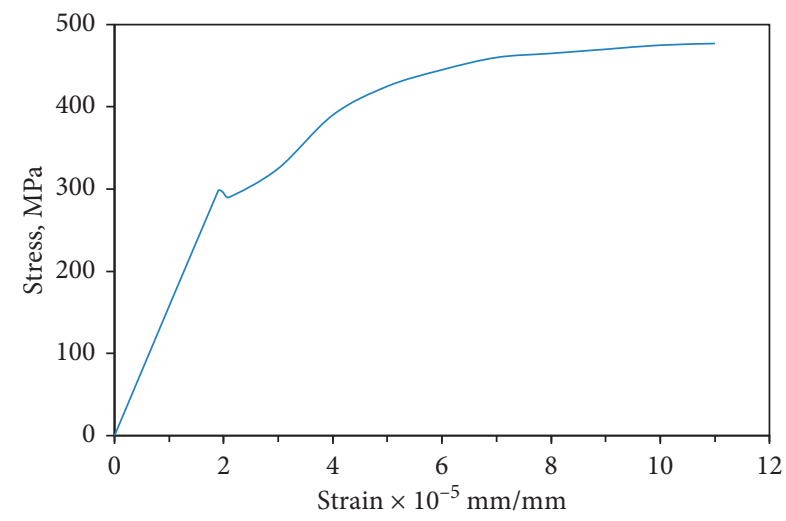

FIGURE 4: Stress-strain relationship of NSM steel bar $(\varnothing 10 \mathrm{~mm})$.

lever arms provided the required eccentricity of $500 \mathrm{~mm}$ with respect to the longitudinal axis of the beam. The I-section steel spreader beam with a $200 \mathrm{~mm}$ depth and $2 \mathrm{~m}$ length was used to transmit the loads from the centre of the machine to the two lever arms as shown in Figure 7. At each load, increment readings were obtained by using the recorded videos and strains from the data logger, whilst the cracks were recorded upon their occurrence.

2.6. NSM Steel Reinforcement Ratio. The NSM steel reinforcement ratios for the strengthened beams are shown in Figure 8. The volumetric ratios of NSM steel bar reinforcement, $\rho_{\text {nst }}$, were calculated by using the following equation:

$$
\rho_{\text {nst }}=\frac{\text { volume of steel tirrup }}{\text { Volume of concrete }}=\frac{A_{\text {nst }} p_{\text {nst }}}{A_{\mathrm{c}} S},
$$

where $\rho_{\text {nst }}$ is area of the NSM steel stirrup reinforcement ratio; $A_{\text {nst }}$ is area of the NSM steel stirrup reinforcement; $P_{\text {nst }}$ is perimeter of the NSM steel stirrup; $A_{\mathrm{c}}$ is the gross area of the concrete cross section; and $S$ is $\mathrm{c} / \mathrm{c}$ spacing of the NSM steel stirrups.

2.7. Twist Angle Measurements. The twist angle was measured by using a dial gauge that was connected to the bottom of lever arm at a point $(500 \mathrm{~mm})$ from the centre of the longitudinal axis of the beam as shown in Figure 9. This dial gauge recorded the downward value of the lever arm to determine the twist angle in radians.

\section{Results and Discussion}

The cracking torque $\left(T_{\mathrm{cr}}\right)$, ultimate torque $\left(T_{\mathrm{u}}\right)$, and ultimate twist angle $\left(\theta_{\mathrm{u}}\right)$ of the concrete beams are presented in Table 3. $T_{\mathrm{cr}}, T_{\mathrm{u}}$, and $\theta_{\mathrm{u}}$ of the concrete beams have been significantly improved with the use of NSM steel bars.

3.1. Ultimate Torsional Moment Carrying Capacity. The ultimate torsional moment carrying capacities of the control and strengthened beams are shown in Figure 10. The ultimate torsional moment carrying capacity of the strengthened beams nonlinearly improved relative to the control beam. Beam NSM100 has the maximum ultimate torsional moment $(15.5 \mathrm{kN} \cdot \mathrm{m})$, beam DNSM200 has the minimum torsional moment $(11.25 \mathrm{kN} \cdot \mathrm{m})$, and the torsional moments of all the other strengthened beams lie between these two extremes.

The NSM steel reinforcement ratios for the strengthened beams and the corresponding increase in their ultimate 
TABLE 1: Mechanical properties of the concrete and NSM steel bars.

\begin{tabular}{lcc}
\hline Material & Compressive strength (MPa) & Yielding tensile strength (MPa) \\
\hline Concrete & 48 & - \\
Steel bars $\varnothing 10 \mathrm{~mm}$ & - & 541 \\
Welding steel bars $\varnothing 10 \mathrm{~mm}$ & - & 298 \\
\hline
\end{tabular}

TABLE 2: Sikadur ${ }^{\circledR}-30$ LP (two-part epoxy impregnation resin).

\begin{tabular}{lc}
\hline Appearance and colours & Part A: white; part B: black; parts A+B: light grey \\
\hline Density (at $\left.23^{\circ} \mathrm{C}\right)$ & $\sim 1.65 \mathrm{~kg} / \mathrm{lt}($ parts $\mathrm{A}+\mathrm{B})$ \\
Mixing ratio & Part A: $\mathrm{B}=3: 1$ by weight or volume \\
Layer thickness & $30 \mathrm{~mm}$ max \\
Open time & 90 minutes $\left(\right.$ at $\left.+25^{\circ} \mathrm{C}\right)$ \\
Viscosity & Pasty, not flowable \\
Service temperature & $-40^{\circ} \mathrm{C}$ to $+45^{\circ} \mathrm{C}$ (when cured at $\left.>+23^{\circ} \mathrm{C}\right)$ \\
Tensile strength & $17 \mathrm{MPa}$ to $21 \mathrm{MPa}\left[+40^{\circ} \mathrm{C}\right.$ to $+55^{\circ} \mathrm{C}(7$ days $\left.)\right]$ \\
Shear strength & $15 \mathrm{MPa}$ to $18 \mathrm{MPa}\left(\right.$ when cured for seven days at $\left.+23^{\circ} \mathrm{C}\right)$ \\
\hline
\end{tabular}
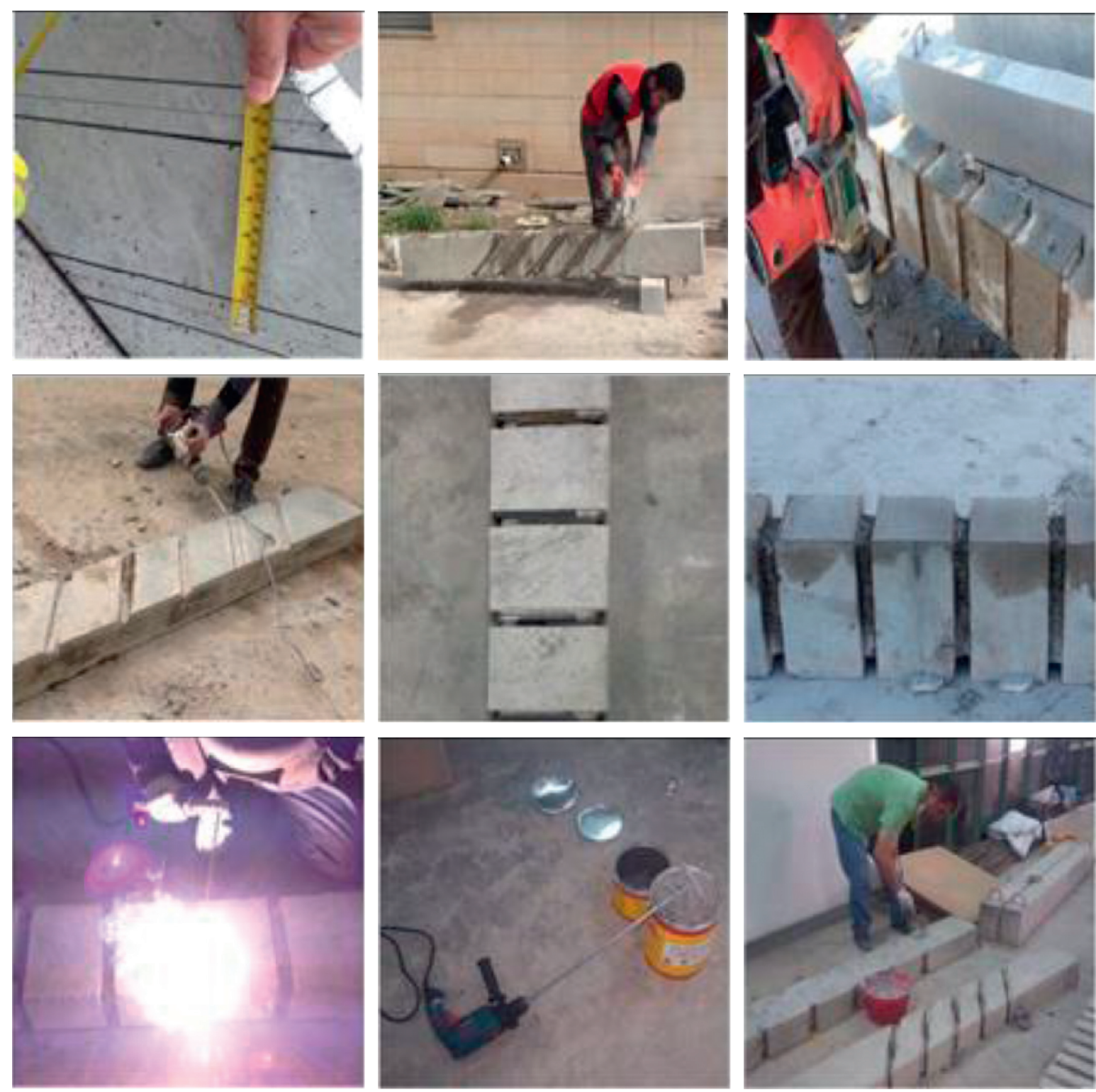

FIGURE 5: Grooving, NSN steel bar installation, welding, and groove filling with epoxy. 


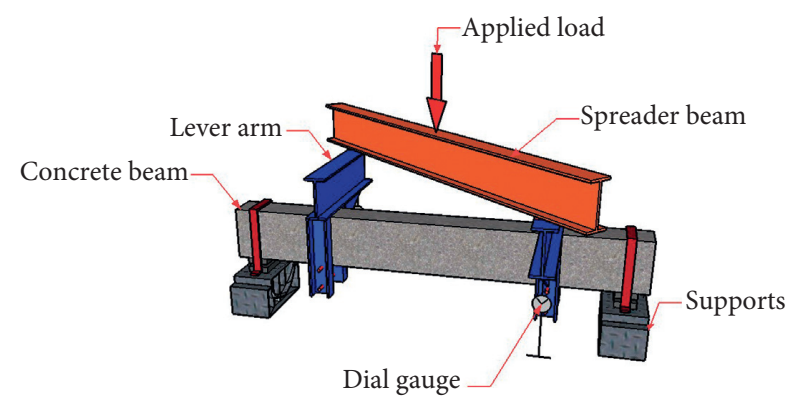

FIGURE 6: Schematic diagram of the test set-up for applying combined torsion and bending.



Figure 7: Test set-up with the loading frame.

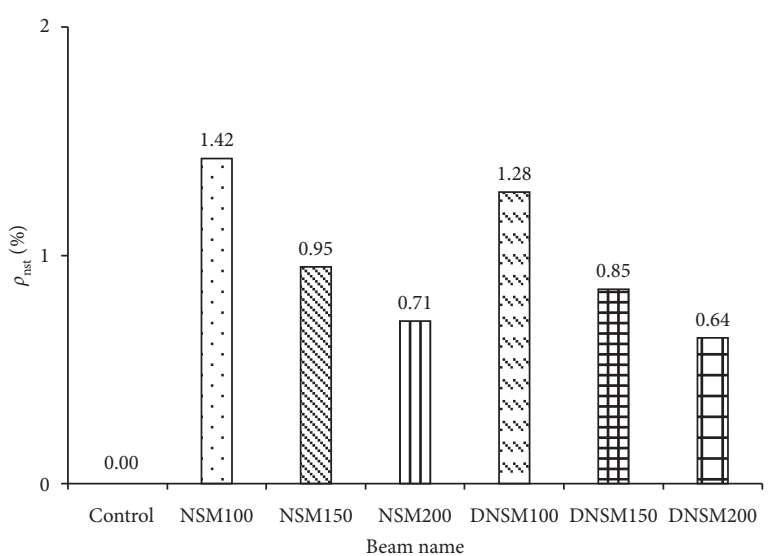

FIGURE 8: NSM steel reinforcement ratios for the strengthened beams.

torsional moment $\left(T_{\mathrm{u}}\right)$ with respect to the control beam are shown in Figure 11. Beam NSM100 has the maximum NSM steel reinforcement ratio (1.42\%) and maximum increase in ultimate torsional moment (44.19\%) relative to the control beam, whilst beam DNSM200 has the minimum NSM steel reinforcement ratio $(0.64 \%)$ and minimum increase in ultimate torsional moment (4.65\%). DNSM100 and DNSM150 have diagonal NSM steel reinforcement ratios of $1.28 \%$ and $0.85 \%$, respectively, and show $22.23 \%$ and $12.33 \%$ improvements in their ultimate torsional moment. However, these improvements are less than those obtained by NSM150 and NSM200 (37.21\% and $33.49 \%$, respectively), which have vertical NSM steel reinforcement ratios of $0.95 \%$ and $0.71 \%$, respectively, because one leg of diagonal NSM steel bar was parallel to the torsional spiral crack of concrete.

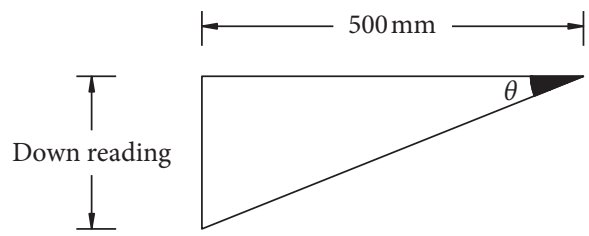

Figure 9: Twist angle measurements.

\subsection{Influence of NSM Steel Bars on Torsional Strength}

3.2.1. Influence of NSM Steel Reinforcement Ratio and Its Inclination on Torsional Strength. The influence of NSM steel reinforcement ratio on the torsional strength of the strengthened beams and the corresponding increase in their ultimate torsional moments $\left(T_{\mathrm{u}}\right)$ relative to the control beam is shown in Figure 12. NSM100, NSM150, and NSM200 have a vertical $\left(90^{\circ}\right)$ NSM steel reinforcement with respect to the longitudinal axis and their corresponding ratios are $1.42 \%, 0.95 \%$, and $0.71 \%$, respectively. The improvements in their ultimate torsional moments are greater than those achieved by DNSM100, DNSM150, and DNSM200 (1.28\%, 0.85\%, and 0.64\%, respectively), which have a diagonal $\left(45^{\circ}\right) \mathrm{NSM}$ steel reinforcement with respect to the longitudinal axis.

3.2.2. Influence of $c / c$ Spacing and Alignment of NSM Steel Bars on Torsional Strength. Figure 13 shows the effect of the $\mathrm{c} / \mathrm{c}$ spacing of NSM steel bars on increasing the ultimate torsional moment $\left(T_{\mathrm{u}}\right)$ of strengthened beams. As the $\mathrm{c} / \mathrm{c}$ spacing of NSM steel bars decreases, $T_{\mathrm{u}}$ increases in different rates according to the inclination of NSM steel bars $\left(90^{\circ}\right.$ and $\left.45^{\circ}\right) . T_{\mathrm{u}}$ of those beams with a vertical $\left(90^{\circ}\right) \mathrm{NSM}$ and 100 , 150 , and $200 \mathrm{c} / \mathrm{c}$ spacings have improved by $44.19 \%, 37.21 \%$, and $33.49 \%$, respectively, whilst $T_{\mathrm{u}}$ of those beams with an inclined $\left(45^{\circ}\right) \mathrm{NSM}$ and 100,150 , and $200 \mathrm{c} / \mathrm{c}$ spacings has improved by $23.33 \%, 12.33 \%$, and $4.65 \%$, respectively.

3.3. Torque-Twist Comparison. The torque-twist behaviour of the control and strengthened beams is presented Figure 14. The control beam has a lower torque carrying capacity and higher twist angle values compared with those beams strengthened by NSM steel bars under the same load. Ductility in strengthened members arises from delaying cracks as well as resisting tensile forces, which eventually result in increasing the maximum compression strain that concrete can sustain as well as the maximum deformation the structure could undergo. This led us to define the ductility as the increase in the ability of the beam to sustain larger deformations (angle of twist) without failing in a brittle manner (i.e., increasing the deformability of the beam). For studying the effectiveness of the strengthening techniques on beam ductility, the ratio between the maximum deformations (angle of twist) of the strengthened beams and that of the control beam, twist ratio or improved ductility $(\Delta \vartheta)$, will be used as an indication of the effectiveness of the strengthening systems, as shown in Table 4. For beams strengthened with NSM steel bar, because of high 
TABLe 3: Experimental results of the tested beams.

\begin{tabular}{|c|c|c|c|c|c|c|c|c|}
\hline Beam code & Str. tech. & $f^{\prime} c(\mathrm{MPa})$ & $T_{\mathrm{cr}}(\mathrm{kN} \cdot \mathrm{m})$ & \%incr. $T_{\mathrm{cr}}$ & $\mathrm{Tu}(\mathrm{kN} \cdot \mathrm{m})$ & \%incr. $T_{\mathrm{u}}$ & $\theta_{\mathrm{u}}($ deg. $/ \mathrm{m})$ & $\%$ dec. $\theta_{\mathrm{u}}$ \\
\hline Control & Un-str. & & 4.50 & . & 10.75 & 0.00 & 4.77 & 0.00 \\
\hline NSM100 & & & 8.50 & 88.89 & 15.50 & 44.19 & 3.97 & 16.77 \\
\hline NSM150 & & & 8.00 & 77.78 & 14.75 & 37.21 & 3.64 & 23.69 \\
\hline NSM200 & NSM steel bor & 48 & 7.00 & 55.56 & 14.35 & 33.49 & 3.47 & 27.25 \\
\hline DNSM100 & NSIn sleer dar & & 7.50 & 66.67 & 13.15 & 22.33 & 4.35 & 8.81 \\
\hline DNSM150 & & & 7.00 & 55.56 & 12.08 & 12.33 & 3.82 & 19.92 \\
\hline DNSM200 & & & 7.00 & 55.56 & 11.25 & 4.65 & 2.73 & 42.77 \\
\hline
\end{tabular}

Str. Tech. is strengthening technique; $f^{\prime} c$ is concrete compressive strength; $T_{\mathrm{cr}}$ is cracking torque; $\%$ Incr. $T_{\mathrm{cr}}$ is percentage increase in cracking torque; $T_{\mathrm{u}}$ is ultimate torque; \%Incr. $T_{\mathrm{u}}$ is percentage increase in ultimate torque; $\theta_{\mathrm{u}}$ is ultimate twist angle; \%dec. $\theta_{\mathrm{u}}$ is percentage decrease in ultimate twist angle; "Un-str." is short for "unstrengthened."

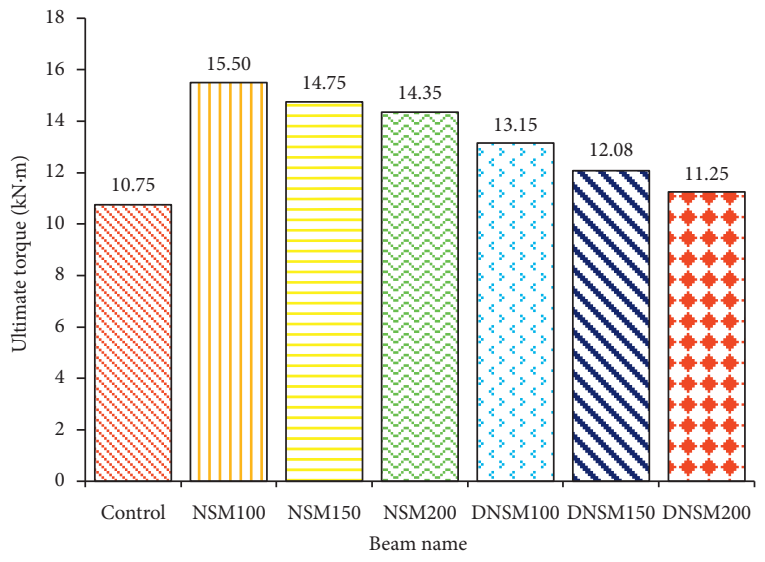

FIGURE 10: Ultimate torsional moment carrying capacities of the beam specimens.

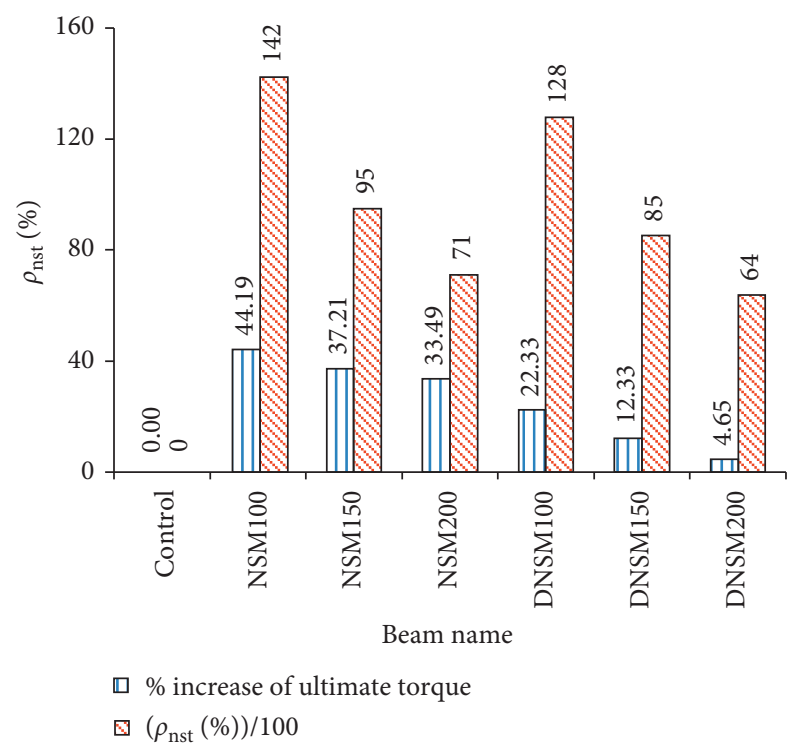

Figure 11: NSM steel ratios and percentage improvements in the ultimate torque of the beam specimens.

stirrup reinforcement ratio (i.e., reinforcement ratio of internal stirrup plus that from NSM welded steel bar), twist ratio or improved ductility $(\Delta \vartheta)$ decreased; its values for NSM100, NSM150, NSM200, DNSM100, DNSM150, and DNSM200 are $0.83,0.76,0.73,0.91,0.80$, and 0.57, respectively.
Those beams that were strengthened by NSM steel bars with a vertical $\left(90^{\circ}\right)$ alignment with respect to the longitudinal axis (NSM100, NSM150, and NSM200) show a different ductility compared with those beams that were strengthened by NSM steel bars with a diagonal $\left(45^{\circ}\right)$ alignment with respect to the longitudinal axis (DNSM100, DNSM150, and DNSM200).

Furthermore, the torque-twist angle tendency of all beams does not show any significant changes before the cracking. In the postcracking stage, all curves show a reliable slope to reach the ultimate torque of beams due to the stirrup or the external NSM steel reinforcement that resists the torque loaded on the beams. Consequently, the torsional rigidity of the beams increases and the loading stops after reaching the ultimate torque.

3.4. Crack Pattern and Failure Modes. The failure modes of the NSM-steel-bar-strengthened reinforced concrete beams under combined bending and torsion are presented in Figure 15. All tested beams demonstrated failure as a result of torsional moment. The number of cracks in the strengthened beams was larger than that in the control beam. Therefore, the strengthened beams demonstrated a higher tensile stress, whilst the control beam showed flexural cracks at the mid-length of one or both of its vertical faces. Tension cracks were also generated and propagated in a spiral formation. These cracks gradually widened along with an increasing load, with the two lever arms rotating relative to one another around the RC beam centroidal axis along with bending. Most of the concrete cracks in the strengthened beams were dispersed through the concrete surfaces between the NSM steel bar grooves. In addition, the NSM steel bar yielded in all specimens and the RC beam demonstrated sudden failure after the crushing of concrete.

In NSM100, the first crack appeared at the edge of the test region in both sides near the lever arm. This crack propagated very slowly and dispersed throughout the test region in a spiral formation immediately before the failure caused by the main crack near the lever arm was widened to approximately $6 \mathrm{~mm}$. For NSM150, the first crack appeared at the centre of the test region and in both sides of the specimen; these cracks propagated and dispersed throughout the central portion of the test region in a spiral formation and the widening of the main crack at the centre of the test region resulted in a failure. For NSM200, the first crack 


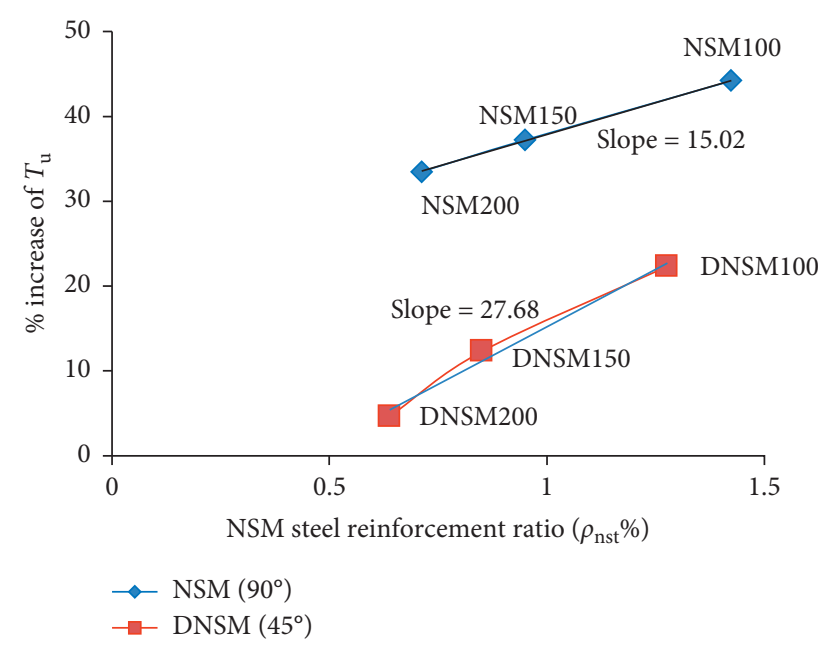

FIGURE 12: Influence of NSM steel reinforcement ratio on the torsional strength of concrete beams.



FIgURE 13: Influence of NSM alignments on $T_{\mathrm{u}}$.

appeared at a quarter length in both sides of the test region and resulted in a failure.

DNSM100, DNSM150, and DNSM200 showed different crack formation, crack propagation, and failure modes. These cracks initially appeared at that face which diagonal NSM steel bar had direction parallel to the spirally cracks, because, at that face, the diagonal NSM steel bar did not work. The cracks in this side propagated wide by approximately $1 \mathrm{~mm}-2 \mathrm{~mm}$ and then cracks started to form at the opposite side and in various directions, although not in a spiral formation. For those beams with an inclined $\left(45^{\circ}\right) \mathrm{NSM}$ steel bar, the failure occurred at that face which diagonal NSM steel bar had direction parallel to the spirally cracks. Generally, the number of cracks for the strengthened beams with a diagonal $\left(45^{\circ}\right)$ NSM steel bar was less than that of the strengthened beams with a vertical $\left(90^{\circ}\right)$ NSM steel bar.

\section{Analytical Analysis}

The full torsional strength of the NSM-strengthened RC beams can be analysed by the design codes using the

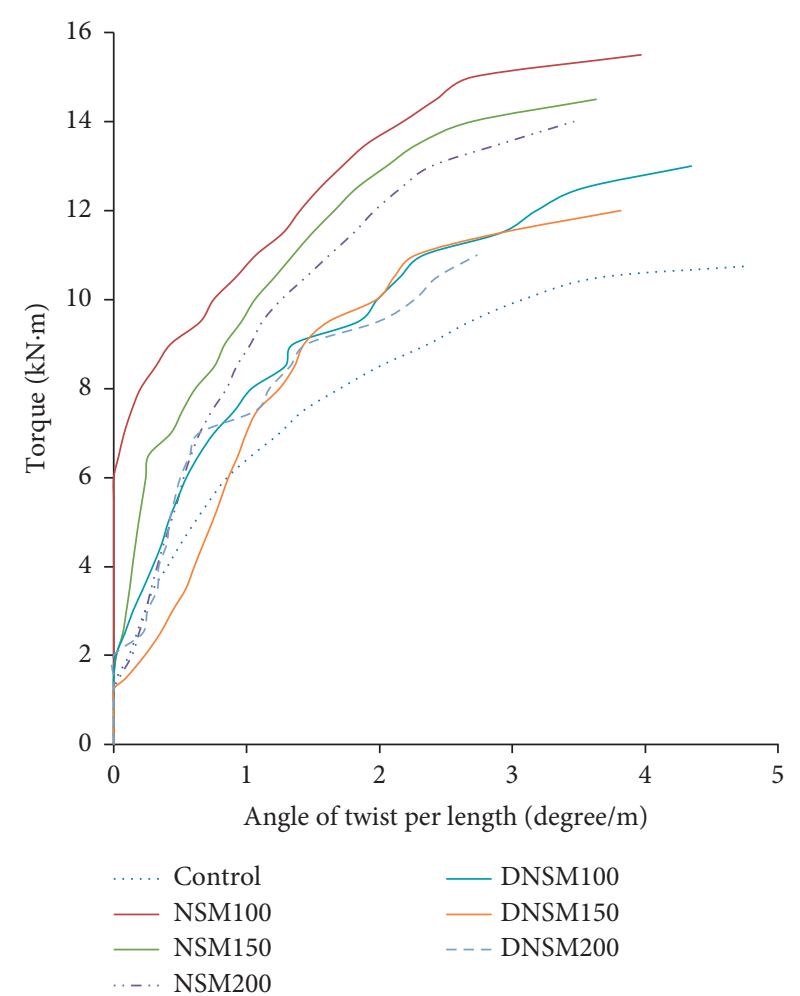

FIgURE 14: Torque versus twist angle of each concrete beam.

TABle 4: Specimens' twist ratio.

\begin{tabular}{lcccc}
\hline Beam code & Strengthening type & $\vartheta_{\mathrm{u}}$ & $\Delta \vartheta$ & Mean of $\Delta \vartheta$ \\
\hline Control & Unstrengthened & 4.77 & 1.00 & 1.00 \\
NSM100 & & 3.97 & 0.83 & \\
NSM150 & & 3.64 & 0.76 & \\
NSM200 & NSM welded steel bar & 3.47 & 0.73 & 0.77 \\
DNSM100 & & 4.35 & 0.91 & \\
DNSM150 & & 3.82 & 0.80 & \\
DNSM200 & & 2.73 & 0.57 & \\
\hline
\end{tabular}

superposition principle of both the NSM steel bar and internal steel stirrups.

$T_{\mathrm{u}}$ of the NSM-strengthened tested beams can be calculated as in equation (2) by adding the contributions of the NSM steel bar and the reinforced concrete beam:

$$
T_{\mathrm{u}}=T_{\mathrm{u}, \mathrm{RC}}+T_{\mathrm{u}, \mathrm{NSM}},
$$

where $T_{\mathrm{u}}$ denotes the nominal torsional capacity of the NSM-strengthened beam, $T_{\mathrm{u}, \mathrm{RC}}$ denotes the ultimate torsional capacity from steel reinforcement, and $T_{\mathrm{u}, \mathrm{NSM}}$ denotes the ultimate torsional capacity from NSM reinforcement.

$T_{\mathrm{u}, \mathrm{RC}}$ and $T_{\mathrm{u}, \mathrm{NSM}}$ are calculated as in equations (3) and (4), respectively, according to the recommendations of ACI 318-14 [33]:

$$
T_{\mathrm{u}, \mathrm{RC}}=\frac{2(0.85) \cdot A_{\mathrm{o}} \cdot A_{\mathrm{t}} \cdot f_{\mathrm{yv}}}{S},
$$

where $A_{\mathrm{o}}$ denotes the cross-sectional area bounded by the centre line of the shear flow according to ACI 318-14, $A_{\mathrm{t}}$ denotes the area of transversal steel reinforcement (stirrups), 


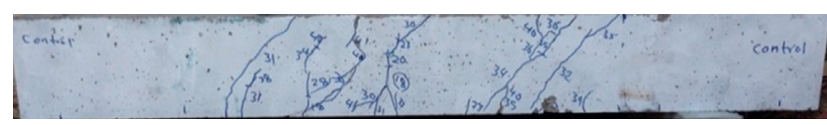

(a)

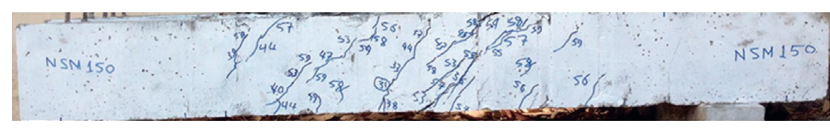

(c)

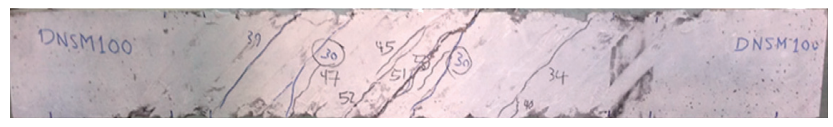

(e)

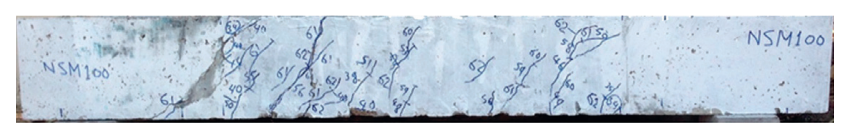

(b)

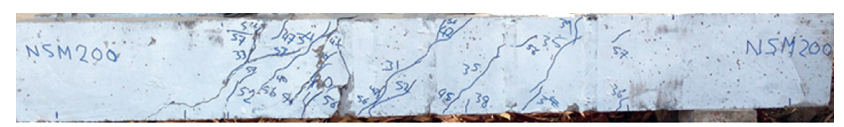

(d)

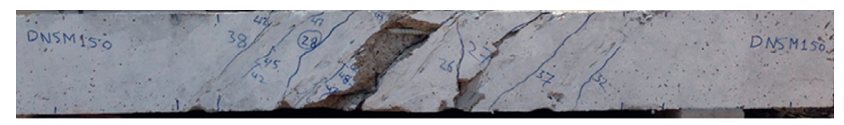

(f)



(g)

FIGURE 15: Failure modes of specimens under combined torsion and bending: (a) control specimen; (b) NSM100; (c) NSM150; (d) NSM200; (e) DNSM100; (f) DNSM150; and (g) DNSM200.

TABle 5: Comparison of the experimental and analytical ultimate torsional moments.

\begin{tabular}{lccc}
\hline \multirow{4}{*}{ Beam code } & \multicolumn{2}{c}{$T_{\mathrm{u}}(\mathrm{kN} \cdot \mathrm{m})$} & \\
& Experimental & Analytical & \\
\hline Control & 10.75 & 6.18 & 1.74 \\
NSM100 & 15.50 & 18.81 & 0.82 \\
NSM150 & 14.75 & 14.60 & 1.01 \\
NSM200 & 14.35 & 12.49 & 1.15 \\
DNSM100 & 13.15 & 12.49 & 1.05 \\
DNSM150 & 12.08 & 10.39 & 1.16 \\
DNSM200 & 11.25 & 9.34 & 1.20 \\
\hline
\end{tabular}

$T_{\mathrm{u}, \text { Exp }}$ : experimental ultimate torsional moment; $T_{\mathrm{u}, \mathrm{An}}$ : analytical ultimate torsional moment.

$f_{\mathrm{yv}}$ denotes the yield stress of transversal steel reinforcement, and $S$ denotes the spacing of stirrups:

$$
T_{\mathrm{u}, \mathrm{NSM}}=\frac{2(0.85) \cdot A_{\mathrm{o}, \mathrm{NSM}} \cdot A_{\mathrm{t}, \mathrm{NSM}} \cdot f_{\mathrm{yv}, \mathrm{NSM}}}{S_{\mathrm{NSM}} / \sin \varnothing},
$$

where $A_{\mathrm{o} \text { NSM }}$ denotes the cross-sectional area bounded by the centre line of the shear flow (NSM-welded steel bar stirrup) according to ACI 318-14, $A_{\mathrm{t}, \mathrm{NSM}}$ denotes the area of the NSM-welded steel reinforcement (stirrups), $f_{\mathrm{yv}, \mathrm{NSM}}$ denotes the yield stress of the NSM-welded steel reinforcement, and $S_{\text {NSM }}$ denotes the horizontal spacing of the NSM-welded stirrups. $\varnothing$ is the angle (inclination) between NSM steel bar reinforcement and the longitudinal axis of the beam ( $\varnothing=90^{\circ}$ for vertical NSM steel bars; $\varnothing=45^{\circ}$ for inclined NSM steel bars).

Table 5 and Figure 16 compare the experimental and the predicted results for torsional capacity using the ACI 318$14 \mathrm{M}$ design model equations. The torsional capacity for the control beam was underestimated by $74 \%$ because the model was established based on space truss theory, which ignores the contribution of the concrete core to the torsional capacity. Moreover, the aggregate interlock, which has an

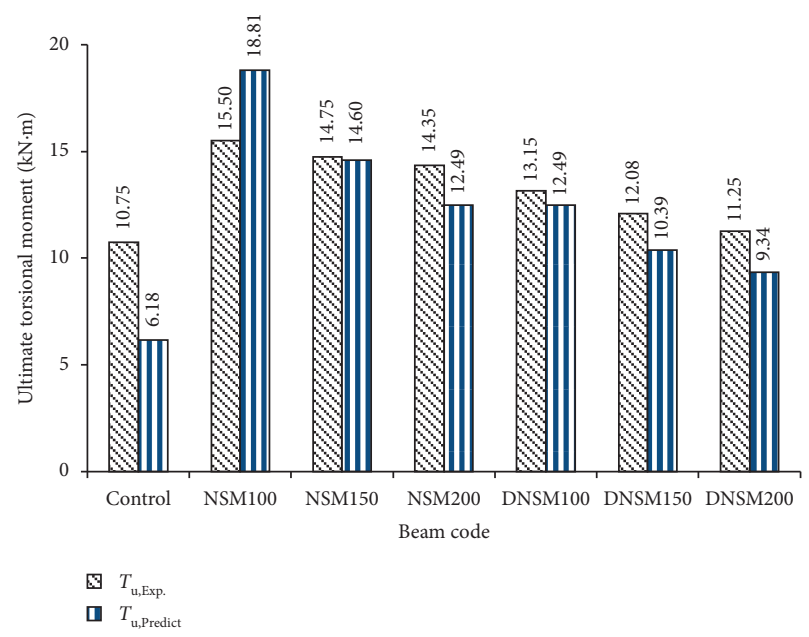

FIgURE 16: Experimental versus analytical ultimate torsional moments at each concrete beam.

additive effect on the torsional capacity of RC beams, is ignored in this model.

For the strengthened RC beams NSM150 and DNSM100, the predicted ultimate torsional moment values show good agreement with the experimental results. However, for the strengthened beams NSM200, DNSM150, and DNSM200, the predicted values are obviously lower than the experimental values. By contrast, for the strengthened beam NSM100, the predicted values are obviously higher than the experimental values.

\section{Conclusions}

Apart from the shear and flexural strength of RC beams, this study examines the torsional behaviour of RC beams that were strengthened with various NSM steel bar configurations under the combined effect of torsion and bending. The 
following conclusions can be drawn from the experimental results:

(i) All beams strengthened by the NSM steel bar showed a higher torsional resistance compared with the control beam regardless of the NSM steel bar configurations and angle of inclination $\left(45^{\circ}\right.$ and $90^{\circ}$ ) with respect to the longitudinal axis

(ii) Compared with the other strengthening configurations for the NSM steel bar, the $90^{\circ} \mathrm{NSM}$ steel bar configuration was identified as a more effective system for strengthening RC beams compared with the $45^{\circ} \mathrm{NSM}$ steel bar configuration in terms of the torsion resistance, because, at that face, the diagonal NSM steel bar had direction parallel to the spirally cracks, For this reason, the diagonal NSM steel bar did not work at that face

(iii) The NSM100 test beam, which has a $\varnothing 10 \mathrm{~mm}$ welded NSM steel bar, $90^{\circ}$ angle of inclination, and $100 \mathrm{~mm}$ spacing, showed the maximum (44.19\%) increment in ultimate torque, whilst the DNSM200 beam, which has a $\varnothing 10 \mathrm{~mm}$ welded NSM steel bar, $45^{\circ}$ angle of inclination, and $200 \mathrm{~mm}$ spacing, showed the minimum (4.65\%) increment in ultimate torque compared with the control beam

(iv) The NSM100 test beam, which has a $\varnothing 10 \mathrm{~mm}$ welded NSM steel bar, $90^{\circ}$ angle of inclination, and $100 \mathrm{~mm}$ spacing, showed the maximum $(88.89 \%)$ increment in cracking torque, whilst the DNSM150 and DNSM200 beams, which have a $\varnothing 10 \mathrm{~mm}$ welded NSM steel bar, $45^{\circ}$ angle of inclination, and $150 \mathrm{~mm}$ and $200 \mathrm{~mm}$ spacings, showed the minimum (55.56\%) increment in cracking torque compared with the control beam

(v) The ductility of all strengthened beams decreased and such reduction was significant for some NSM steel bar configurations

(vi) The percentage increase in $T_{\mathrm{u}}$ proportionally increased along with the NSM steel bar ratio

(vii) Generally, the cracks in the strengthened beams extensively spread along with the beam length compared with the singular cracks formed in the control beam

(viii) The concrete beam failure was delayed for those beams strengthened with NSM steel bars. However, such failure occurred in the unstrengthened region space between the NSM steel bars

(ix) The ultimate torsional moment increased by reducing the spacing between the NSM steel bars (i.e., increasing the NSM steel bar)

(x) The predicted ultimate torsional moment of those RC beams strengthened by the NSM-welded steel bar with moderate spacing showed good agreement with the experimental results

\section{Data Availability}

The data used to support the findings of this study are included within the article.

\section{Disclosure}

The funders had no role in the design of the study, in the collection, analyses, or interpretation of data, in the writing of the manuscript, and in the decision to publish the results.

\section{Conflicts of Interest}

The authors declare no conflicts of interest.

\section{Authors' Contributions}

Both authors conceived and designed the experiments; Nasih Habeeb Askandar analysed the data and wrote the paper, whilst Abdulkareem Darweesh Mahmood revised the manuscript.

\section{Acknowledgments}

The authors acknowledge the support of Salahaddin University-Erbil and Sulaimani Polytechnic University in Sulaymaniyah.

\section{References}

[1] ACI 440.2R-08, Guide for the Design and Construction of Externally Bonded FRP Systems for Strengthening Concrete Structures, American Concrete Institute, Farmington Hills, MI, U.S.A, 2008.

[2] L. De Lorenzis and J. G. Teng, "Near-surface mounted FRP reinforcement: an emerging technique for strengthening structures," Composites Part B: Engineering, vol. 38, no. 2, pp. 119-143, 2007.

[3] A. Mofidi, O. Chaallal, L. Cheng, and Y. Shao, "Investigation of near surface-mounted method for shear rehabilitation of reinforced concrete beams using fiber reinforced-polymer composites," Journal of Composites for Construction, vol. 20, no. 2, Article ID 04015048, 2015.

[4] M. Ramezanpour, R. Morshed, and A. Eslami, "Experimental investigation on optimal shear strengthening of RC beams using NSM GFRP bars," Structural Engineering Mechanics, vol. 67, no. 1, pp. 45-52, 2018.

[5] B. Almassri, Strengthening of Corroded Reinforced Concrete (RC) Beams with Near Surface Mounted (NSM) Technique Using Carbon Fiber Polymer (CFRP) Rods; An Experimental and Finite Element (FE) Modelling Study, INSA, Toulouse, France, 2015.

[6] V. S. Kuntal, M. Chellapandian, and S. S. Prakash, "Efficient near surface mounted CFRP shear strengthening of high strength prestressed concrete beams-an experimental study," Composite Structures, vol. 180, pp. 16-28, 2017.

[7] G. Wu, Z.-Q. Dong, Z.-S. Wu, and L.-W. Zhang, "Performance and parametric analysis of flexural strengthening for RC beams with NSM-CFRP bars," Journal of Composites for Construction, vol. 18, no. 4, Article ID 04013051, 2014.

[8] I. A. Sharaky, L. Torres, J. Comas, and C. Barris, "Flexural response of reinforced concrete (RC) beams strengthened with near surface mounted (NSM) fibre reinforced polymer (FRP) bars," Composite Structures, vol. 109, pp. 8-22, 2014.

[9] N. Kishi, "Flexural behaviour of RC beams reinforced with NSM AFRP rods," in Proceedings of the 2005 International Symposium on Bond Behaviour of FRP in Structures, Hong Kong, China, December 2005. 
[10] S. Gopinath, A. R. Murthy, and H. Patrawala, "Near surface mounted strengthening of RC beams using basalt fiber reinforced polymer bars," Construction and Building Materials, vol. 111, pp. 1-8, 2016.

[11] F. Al-Mahmoud, A. Castel, R. François, and C. Tourneur, "RC beams strengthened with NSM CFRP rods and modeling of peeling-off failure," Composite Structures, vol. 92, no. 8, pp. 1920-1930, 2010.

[12] I. A. Sharaky, R. M. Reda, M. Ghanem, M. H. Seleem, and H. E. M. Sallam, "Experimental and numerical study of RC beams strengthened with bottom and side NSM GFRP bars having different end conditions," Construction and Building Materials, vol. 149, pp. 882-903, 2017.

[13] J. Barros, S. Dias, and A. Fortes, "Near surface mounted technique for the flexural and shear strengthening of concrete beams," in Proceedings of the 2005 International Conference on Concrete for Structures, University of Coimbra, Coimbra, Portugal, pp. 229-236, 2005.

[14] R. El-Haca and M. Gaafar, "Flexural strengthening of reinforced concrete beams using prestressed, near-surfacemounted CFRP bars," PCI Journal, vol. 56, no. 4, pp. 134-151, 2011.

[15] M. Hosen, U. J. Alengaram, M. Z. Jumaat, N. H. R. Sulong, and K. M. U. Darain, "Glass fiber reinforced polymer (GFRP) bars for enhancing the flexural performance of RC beams using side-NSM technique," Polymers, vol. 9, no. 12, p. 180, 2017.

[16] S. S. Zhang, T. Yu, and G. M. Chen, "Reinforced concrete beams strengthened in flexure with near-surface mounted (NSM) CFRP strips: current status and research needs," Composites Part B: Engineering, vol. 131, pp. 30-42, 2017.

[17] A. A. Shukri, M. A. Hosen, R. Muhamad, and M. Z. Jumaat, "Behaviour of precracked RC beams strengthened using the side-NSM technique," Construction and Building Materials, vol. 123, pp. 617-626, 2016.

[18] A. Ghanim and B. Al-Abbas, "Experimental study on the flexural strengthening of reinforced concrete beams using NSM CFRP bars," in Proceedings of the 5th national and 1st International Conference on Modern Materials and Structures in Civil Engineering, Amirkabir University of Technology, Tehran, Iran, 2018.

[19] W.-T. Jung, J.-S. Park, J.-Y. Kang, and H. B. Park, "Strengthening effect of prestressed near-surface-mounted CFRP tendon on reinforced concrete beam," Advances in Materials Science and Engineering, vol. 2018, Article ID 9210827, 18 pages, 2018.

[20] W.-T. Jung, J.-S. Park, J.-Y. Kang, and M.-S. Keum, "Flexural behavior of concrete beam strengthened by near-surface mounted CFRP reinforcement using equivalent section model," Advances in Materials Science and Engineering, vol. 2017, Article ID 9180624, 16 pages, 2017.

[21] D. A. Bournas and T. C. Triantafillou, "Flexural strengthening of RC columns with NSM FRP or stainless steel," ACI Structural Journal, vol. 106, no. 4, pp. 495-505, 2009.

[22] M. Chellapandian, S. S. Prakash, and A. Sharma, "Experimental and finite element studies on the flexural behavior of reinforced concrete elements strengthened with hybrid FRP technique," Composite Structures, vol. 208, pp. 466-478, 2019.

[23] H. H. Kammona and A. S. H. Al-Issawi, "Estimation of maximum shear capacity of RC deep beams strengthened by NSM steel bars," Journal of University of Babylon, vol. 26, no. 3, pp. 13-22, 2018.

[24] N. Franco, H. Biscaia, and C. Chastre, "Experimental and numerical analyses of flexurally-strengthened concrete
T-beams with stainless steel," Engineering Structures, vol. 172, pp. 981-996, 2018.

[25] M. A. Hosen, "Flexural strengthening of RC beams with NSM steel bars," in Proceedings of the International Conference on Food, Agriculture and Biology (FAB-2014), Kuala Lumpur, Malaysia, June 2014.

[26] M. Breveglieri, A. Aprile, and J. A. O. Barros, "Shear strengthening of reinforced concrete beams strengthened using embedded through section steel bars," Engineering Structures, vol. 81, pp. 76-87, 2014.

[27] K. N. Rahal and H. A. Rumaih, "Tests on reinforced concrete beams strengthened in shear using near surface mounted CFRP and steel bars," Engineering Structures, vol. 33, no. 1, pp. 53-62, 2011.

[28] M. Hosen, M. Jumaat, U. Alengaram, A. Islam, and H. Bin Hashim, "Near surface mounted composites for flexural strengthening of reinforced concrete beams," Polymers, vol. 8, no. 3, p. 67, 2016.

[29] N. Askandar and A. Mahmood, "Comparative investigation on torsional behaviour of RC beam strengthened with CFRP fabric wrapping and near-surface mounted (NSM) steel bar," Advances in Civil Engineering, vol. 2019, Article ID 9061703, 15 pages, 2019.

[30] G. Al-Bayati, R. Al-Mahaidi, and R. Kalfat, "Experimental investigation into the use of NSM FRP to increase the torsional resistance of RC beams using epoxy resins and cementbased adhesives," Construction and Building Materials, vol. 124, pp. 1153-1164, 2016.

[31] G. Al-Bayati, R. Al-Mahaidi, M. J. Hashemi, and R. Kalfat, "Torsional strengthening of RC beams using NSM CFRP rope and innovative adhesives," Composite Structures, vol. 187, pp. 190-202, 2018.

[32] N. H. Askandar and A. D. Mahmood, "Torsional strengthening of RC beams with continuous spiral near-surface mounted steel wire rope," International Journal of Concrete Structures and Materials, vol. 14, pp. 1-16, 2020.

[33] ACI 318M-14, Building Code Requirements for Structural Concrete, American Concrete Institute, Farmington Hills, MI, USA, 2014.

[34] ASTM A370-10, Standard Test Methods and Definitions for Mechanical Testing of Steel Products, ASTM International, West Conshohocken, PA, USA, 2010. 